\title{
A LABORATORY INVESTIGATION AND AN APPRAISAL OF THE VIABILITY OF EXPANDED POLYSTYRENE DWELLINGS
}

\author{
BONKE MNCWANGO \& DHIREN ALLOPI \\ Durban University of Technology.
}

\begin{abstract}
The construction of expanded polystyrene (EPS) dome houses requires intricate moulding equipment. A further obstacle in the accessibility of EPS dome houses is the minimum order placed by suppliers. Japan Dome House Company supplies dome houses at a minimum order of three-hundred units. This publication analyses how a miniature EPS dome house model created using a hot-wire system matches the claimed performance features of a factory-manufactured EPS Dome house. The purpose of this research is to investigate whether EPS dome houses can be created on an individual basis through a change in the construction method in order to increase product accessibility. All EPS dome pieces were carved over a period of 5 days. EPS pieces were assembled and left exposed to the elements since the main method of analysis of the live model was through exposure; particularly against rain and wind experienced within the jurisdiction of Pietermaritzburg, South Africa. Analysis of the live model was studied in conjunction with the compression, flexural and thermal qualities of EPS under laboratory conditions. With wind speeds of $39 \mathrm{~km} / \mathrm{h}$ and a rainfall intensity of $28 \mathrm{~mm}$, the model was still found to be in its original state of composure after three months even without having been permanently anchored to the ground. Observation of the model revealed that it is possible to successfully re-create an EPS dome house without complex moulding equipment. However, a compressive strength test on EPS revealed that the compressive qualities of EPS are significantly lower than that of conventional materials such as clay bricks. Contrary to what may be believed, a thermo-gravimetric analysis of three different densities $\left(15,20\right.$ and $\left.30 \mathrm{~kg} / \mathrm{m}^{3}\right)$ of EPS revealed that as the density of EPS increases, the maximum degradation value decreases. Dome houses are pre-fabricated and therefore have a reduced impact on the environment.

Keywords: Compression, Dome-house, Expanded Polystyrene, Flexural tests, Polymers, TGA.
\end{abstract}

\section{INTRODUCTION}

One of the most astounding thoughts about the consideration of expanded polystyrene (EPS) forming the walls of a house structure is that it is a polymer. Polymers are known to be soft materials which often can be mistaken to be weak. Contrary to this, the Expanded Polystyrene Association of Southern Africa (EPSASA) has shown that a 200mm-thick layer of EPS with a density of $20 \mathrm{~kg} / \mathrm{m}^{3}$ represents the same amount of energy as a $17 \mathrm{~mm}$-thick layer of pine wood [1]. It is commonly believed that a residential dwelling is considered to be 'normal' if it conforms to the conventional 'box' shape. Materials such as masonry and concrete have been considered as 'conventional' building materials due to their frequency of use in this regard. However, due to their increased cost and also their impact on the environment, it is now apparent that new building technologies and materials have to be studied and analysed in greater detail in order to provide the structural confidence and plausible change that is required.

Japan Dome House Co. Ltd. is a prominent supplier of EPS dome houses [2], however, like many other suppliers of various types of products, they have a minimum order quantity (MOQ) of 300 units [2].

MOQs can be said to be a 'necessary evil' because of one of the following reasons: 
- There are numerous MOQs set by the main supplier's subcontractors for the various components and materials of their product;

- The product has a low margin, so the supplier requires the customer to buy a significant amount of that particular product to make it worthwhile to produce.

The main disadvantage of MOQ is that it limits product accessibility and availability. EPS dome houses have excellent thermal insulation, they are lightweight and are easy to construct. Japan Dome House Co. Ltd has developed a technique to only expand the styrene monomers in EPS by $20 \%$ and this has resulted in an extremely durable material [3]. In an effort to increase the accessibility of EPS structures, this research details the creation of an EPS dome house model in order to observe whether an EPS model created out of standard grade EPS material will achieve superior performance objectives similar to those achieved by the re-worked EPS material produced by Japan Dome House Co. Ltd.

\subsection{Limitations}

The aesthetic appeal of the structure from the end-user's perspective (communities, contractors and government agencies, etc.) was not considered in this paper since it would involve an investigation into the social acceptance of dome shaped structures versus quadrilateral structures and various ethical clearances. The cost aspect was not considered as the perspective and motivation for this paper was to first consider the plausibility of standard grade EPS densities as well as the viability of the construction method used to mould the individual pieces of the EPS dome house. Not all the different densities were tested in their moulded form since the EPS model was only composed of a density of $15 \mathrm{~kg} / \mathrm{m}^{3}$.

\subsection{Considerations}

There are numerous threats which exist to any dwelling, these threats include, but are not limited to fire, wind, rain, storms, lightning and earthquakes. Since some of these threats cannot immediately be experienced by the constructed EPS model; it was necessary to conduct laboratory tests to test the compressive strength, thermal stability and flexural strength of EPS. The location of the placement of the model is Pietermaritzburg, South Africa. A resemblance of Pietermaritzburg's low and high points of temperature is depicted in Fig. 1 by Meteoblue [4].

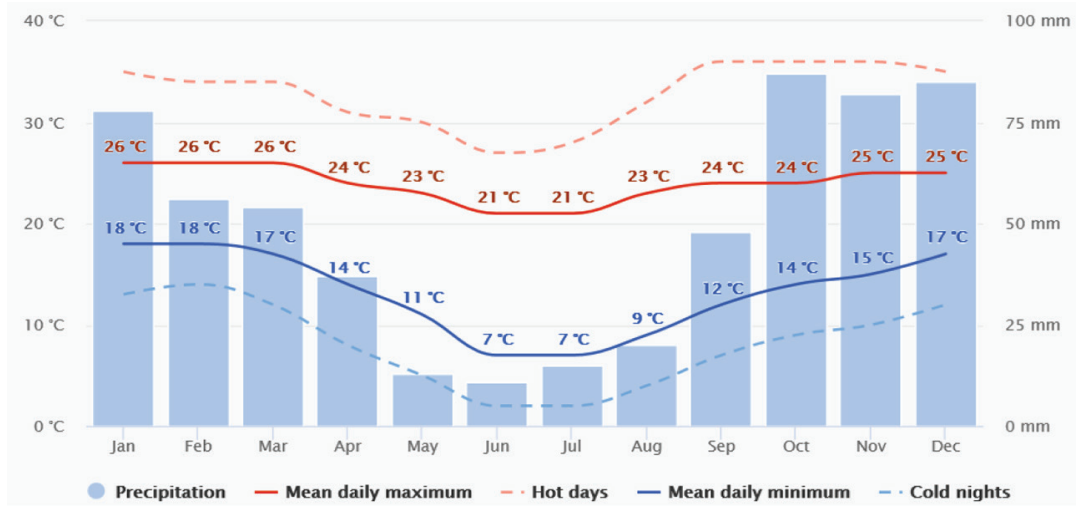

Figure 1: General climate of Pietermaritzburg, KwaZulu-Natal [4]. 


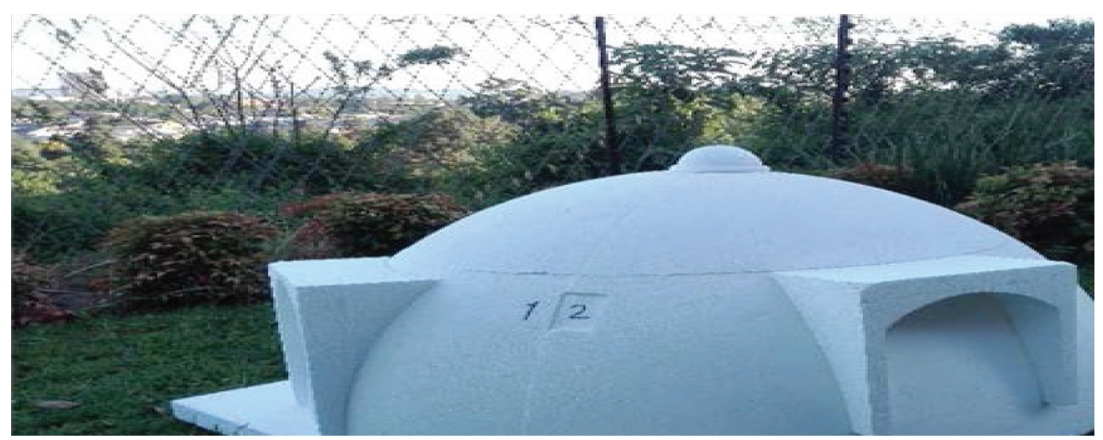

Figure 2: EPS Dome model first placed in February 2018.

\subsection{Field observation}

The dimensions of the model are $1200 \mathrm{~mm}$ diameter $\times 600 \mathrm{~mm}$ carved dome of $15 \mathrm{~kg} / \mathrm{m}^{3}$ density. The shape of the dome was carved through a hot wiring process. The EPS dome house model was placed and exposed to the elements from the 1st of February 2018 to the 30th of April 2018 (three months) as shown in Fig. 2.

\subsection{Discussion}

The highest recorded temperature during the 3-month observation was $36^{\circ}$ on the 2 nd of February 2018. Highest rainfall day was the 16th of March 2018 at $28 \mathrm{~mm}$. Highest wind speeds were experienced on the 2nd of February 2018 at $39 \mathrm{~km} / \mathrm{h}$. Observations made on the model on the 3rd of February 2018 indicate that the high temperature from the previous day did not alter the structural composure of the model in any way. Observations made on the 17th of March 2018 also indicate that no noticeable water penetration could be noted. Figure 3 taken on the 11th of March 2018 indicates that the surface texture remained unaltered. The non-penetration of water by the model is partly due to the material properties of EPS, but also

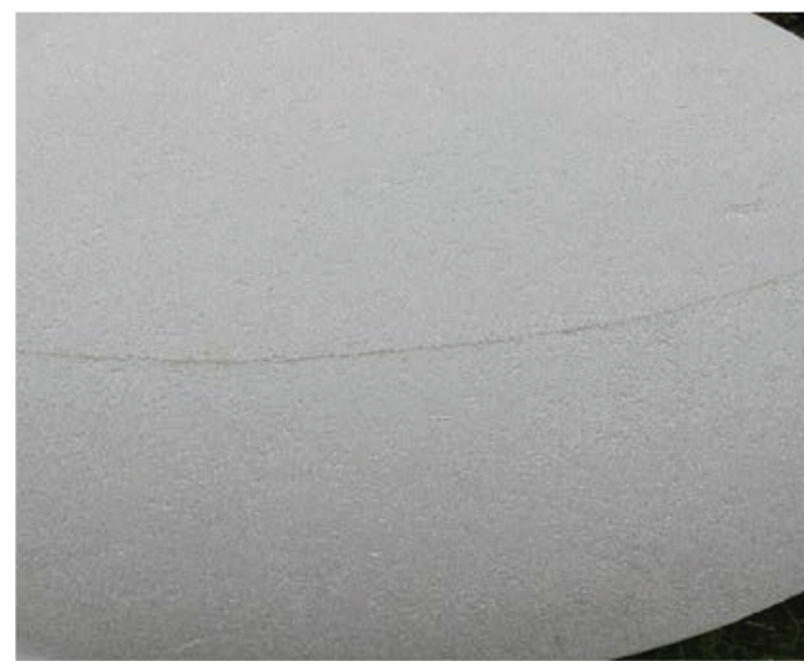

Figure 3: EPS Dome model captured from a different angle in March 2018. 


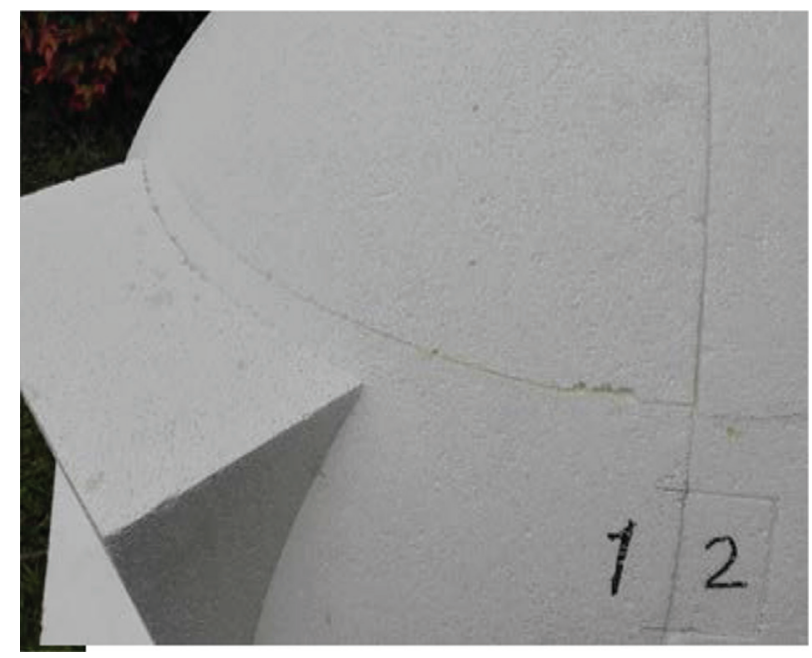

Figure 4: EPS Dome model at close range.

largely due to the shape of the model. Surface water run-off is maximized with a dome shape rather than with a conventional box shape. The model pieces were only inter-locked to each other as shown in Fig. 4, but wind speeds observed on the 2nd of February 2018 did not collapse the model. This was due to wind gusts flowing easily through the curvatures of the model. The lack of any sufficiently large enough surface area for the wind to force itself against, causes it to flow through the model and to continue on its path.

\section{LABORATORY TESTS}

\subsection{Compressive strength}

Lateral and vertical impact is always a concern for any structure. Lateral and vertical impact can be as a result of any airborne object, either in the manner of being self-propelled or assisted, knocking into a structure. The first line of defence for the contents contained in any dwelling is its walls. It is therefore a prerequisite for any sound structure, that the walls must have sufficient compressive strength. In order to test whether standard grade EPS has sufficient compressive strength, a laboratory test was conducted in terms of the ASTM D 1621-00 standard. The apparatus used for the investigation was the Instron 5966-k8883, load indicator as well as the deformation indicator.

\subsubsection{Procedure}

Eight specimens were considered for each density category $\left(15,20\right.$ and $\left.30 \mathrm{~kg} / \mathrm{m}^{3}\right)$. The dimensions of the specimens were measured. A uniformly distributed load was applied to the test specimens at a rate of $2.5 \pm 0.25 \mathrm{~mm} / \mathrm{min}$ for each specimen. The load was applied until yield point or until approx. $13 \%$ of the original thickness was achieved.

Modulus of elasticity in compression is calculated by

$$
E_{c}=W H / A D
$$

The estimated standard deviation is calculated by 


$$
s=\sqrt{\left(\varepsilon x^{2}-n X^{2}\right) /(n-1)}
$$

\subsubsection{Results}

The mean and standard deviation for each different type of density have been detailed in Figs. 5 to 7 and in Tables 1 to 3.

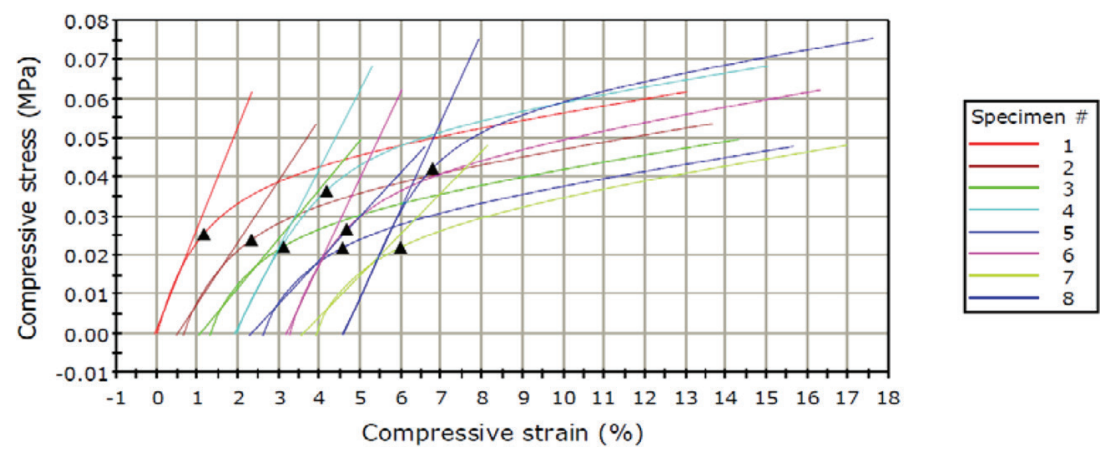

Figure 5: Compressive stress vs compressive strain graph for $15 \mathrm{~kg} / \mathrm{m}^{3}$ samples.

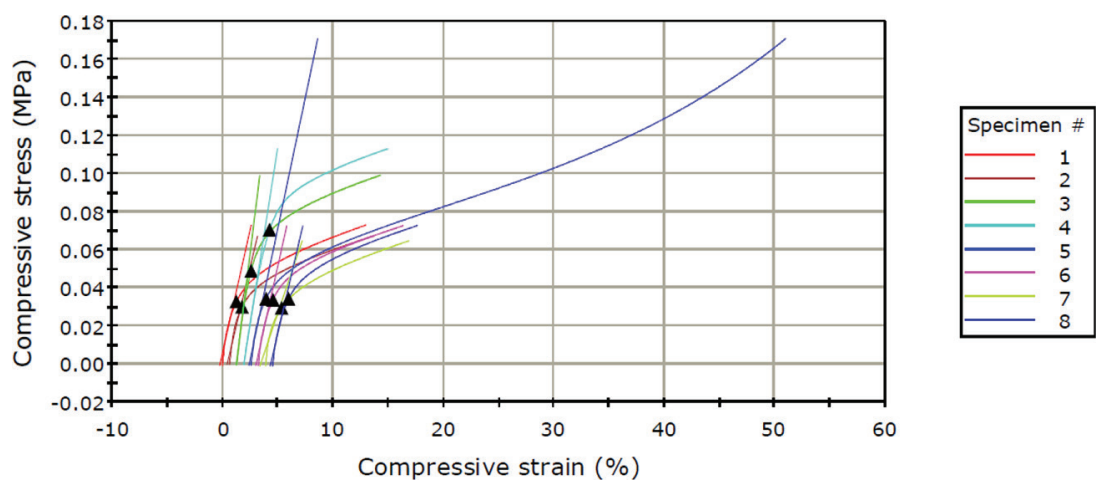

Figure 6: Compressive stress vs compressive strain graph for $20 \mathrm{~kg} / \mathrm{m}^{3}$ samples.
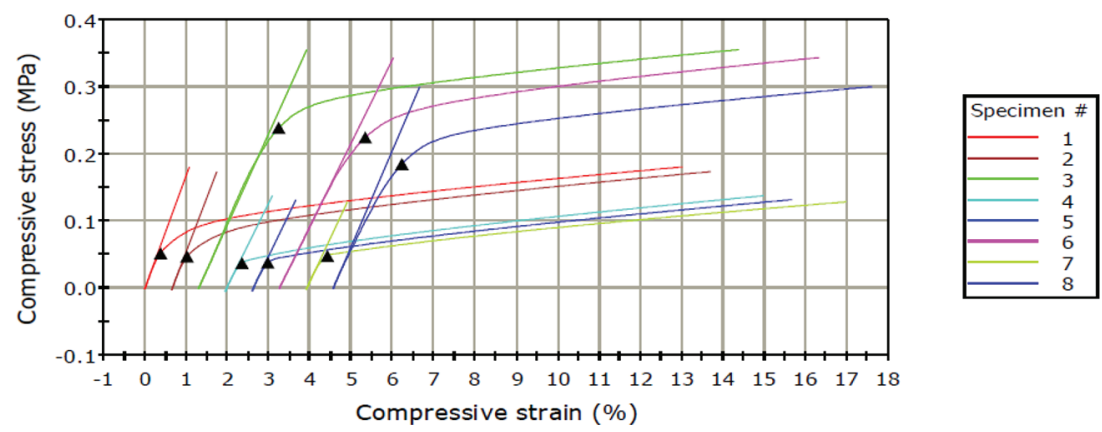

Figure 7: Compressive stress vs compressive strain graph for $30 \mathrm{~kg} / \mathrm{m}^{3}$ samples. 
Table 1: Mean and standard deviation for $15 \mathrm{~kg} / \mathrm{m}^{3}$ density samples.

\begin{tabular}{lccc}
\hline & $\begin{array}{c}\text { Modulus } \\
\text { (E-modulus) }(\mathrm{MPa})\end{array}$ & $\begin{array}{c}\text { Compressive stress } \\
\text { at tensile strength } \\
(\mathrm{MPa})\end{array}$ & $\begin{array}{c}\text { Compressive stress } \\
\text { at yield (zero Slope) } \\
(\mathrm{MPa})\end{array}$ \\
\hline Mean & 1.75 & 0.06 & 0.03 \\
Standard deviation & 0.58 & 0.01 & 0.00 \\
\hline
\end{tabular}

Table 2: Mean and standard deviation for $20 \mathrm{~kg} / \mathrm{m}^{3}$ density samples.

\begin{tabular}{lccc}
\hline & $\begin{array}{c}\text { Modulus } \\
\text { (E-modulus) }(\mathrm{MPa})\end{array}$ & $\begin{array}{c}\text { Compressive stress } \\
\text { at tensile strength } \\
(\mathrm{MPa})\end{array}$ & $\begin{array}{c}\text { Compressive stress } \\
\text { at yield (zero slope) } \\
(\mathrm{MPa})\end{array}$ \\
\hline Mean & 2.87 & 0.09 & 0.04 \\
Standard deviation & 0.89 & 0.04 & 0.01 \\
\hline
\end{tabular}

Table 3: Mean and standard deviation for $30 \mathrm{~kg} / \mathrm{m}^{3}$ density samples.

\begin{tabular}{lccc}
\hline & $\begin{array}{c}\text { Modulus } \\
\text { (E-modulus) }(\mathrm{MPa})\end{array}$ & $\begin{array}{c}\text { Compressive stress } \\
\text { at tensile strength } \\
(\mathrm{MPa})\end{array}$ & $\begin{array}{c}\text { Compressive stress } \\
\text { at yield (zero Slope) } \\
(\mathrm{MPa})\end{array}$ \\
\hline Mean & 13.99 & 0.22 & 0.11 \\
Standard deviation & 1.75 & 0.10 & 0.09 \\
\hline
\end{tabular}

\subsubsection{Discussion}

From the eight specimens for each different density, the three most comparable results from each were considered and are detailed in Table 4. Specimen number 5 in Fig. 6 is an outlier as it deviates significantly from the general pattern of all the other $20 \mathrm{~kg} / \mathrm{m}^{3}$ specimens. One of the most likely causes for this variance is that of material contamination. Material contamination can cause a materials' performance to lie outside of the 'normal' range of performance. Such a specimen indicates that caution should be exercised in the handling of EPS since any contamination may alter its material characteristics and possibly compromise its intended function.

In terms of material variability and also as shown in Fig. 8, the error bar for $30 \mathrm{~kg} / \mathrm{m}^{3}$ density samples indicates that the difference between $30 \mathrm{~kg} / \mathrm{m}^{3}$ and lower densities such as 15 and $20 \mathrm{~kg} / \mathrm{m}^{3}$ differs significantly. Standard deviation error bars for 15 and $20 \mathrm{~kg} / \mathrm{m}^{3}$ show that the difference is statistically not significant and this further means that the characteristics of both densities of 15 and $20 \mathrm{~kg} / \mathrm{m}^{3}$ only differ by a minor degree. Shodhganga [5] states that the modulus of elasticity for three clay brick samples considered during an investigation of compressive strength for clay bricks was $600.6,559.2$ and 574.2 MPa. This shows that the modulus of conventional materials such as clay bricks is significantly higher than the modulus of EPS. However, Japan Dome House Co. Ltd. has shown that EPS can be manipulated during manufacture to yield a much higher density in order to achieve a greater compressive 
Table 4: The three most comparable results indicating the mean modulus for different density

\begin{tabular}{cccc}
\hline Density $\left(\mathrm{kg} / \mathrm{m}^{3}\right)$ & $\begin{array}{c}\text { Mean modulus } \\
\text { (E-modulus) }(\mathrm{MPa})\end{array}$ & $\begin{array}{c}\text { Mean compressive } \\
\text { stress at tensile } \\
\text { strength }(\mathrm{MPa})\end{array}$ & $\begin{array}{c}\text { Mean compressive } \\
\text { stress at yield (zero } \\
\text { slope) }(\mathrm{MPa})\end{array}$ \\
\hline 15 & 1.14 & 0.05 & 0.02 \\
20 & 2.51 & 0.07 & 0.03 \\
30 & 12.56 & 0.20 & 0.10 \\
\hline
\end{tabular}

\section{Mean Modulus (E- modulus) (MPa)}

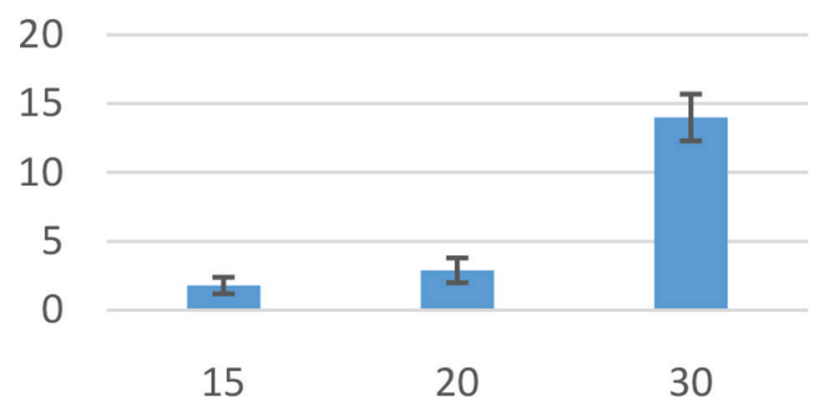

Figure 8: Compressive strength mean modulus graph showing error bars using standard deviation.

strength [3]. Due to the current MOQs imposed by EPS dome house suppliers such as Japan Dome House Co. Ltd., it is evident that the manipulation of this quality of EPS has not yet been conducted in a manner that ensures that the material does not lose its merits of being a viable supplement in the building industry.

\subsection{Thermal stability of EPS}

A phenomenon called 'spontaneous combustion' can be said to be one of the greatest concerns for any property, particularly houses. It therefore remains a high expectation that any building, whether commercial or residential, should be able to adequately 'stand' in the event of any spontaneous fire. Masonry materials are incombustible and therefore inherently effective in providing fire protection for the periods of time specified in building regulations [6].

However, Popular Mechanics [7] had emphasised that as early as the 1970s that no practical building material is truly fireproof. This statement has proved to be consistently true over the years when buildings which were deemed to be 'fire-proof' have gone up in flames.

The diversity of application of EPS might suffice to demonstrate its vast availability, and hence answer the question of being economically efficient; but in order to show its structural suitability, it is necessary to test how it responds to heat and flexural forces. 


\subsubsection{Thermogravimetric analysis: ASTM E 2550-07}

The equipment used for the investigation is the thermo-gravitational analysis (TGA) Q500. A sample of the material to be examined was placed in an inert container and then heated at a controlled rate under a controlled atmosphere. The sample mass was recorded continuously as a function of time and temperature. When the sample underwent a reaction or thermal decomposition involving a mass change that change was indicated by a departure from the initially established baseline of the mass record. The onset temperature and mass changes were determined and recorded.

\subsubsection{Procedure}

The empty specimen container was weighed. The specimen and container were placed into the TGA at ambient temperature. Heat was applied to the specimen at a constant rate of $10^{\circ} \mathrm{C} \mathrm{m^{-1 }}$ and the thermogravimetric curve was recorded. Heating continued until a constant mass was obtained or until the temperature was well above the useful temperature range of the material tested.

\subsubsection{Results}

The TGA analyser shown in Figs. 9 and 10, plotted three line graphs of the performance of all three densities which are presented in Figs. 11 and 12. These line graphs were used to identify the tolerance levels of the varying densities and to further identify the point at which each material begins to degrade.

\subsubsection{Discussion}

Due to minor variations which might exist in the arrangement of the EPS beads within the microstructure of the samples, an average of the three samples for each different density was considered in order to determine the degradation value.

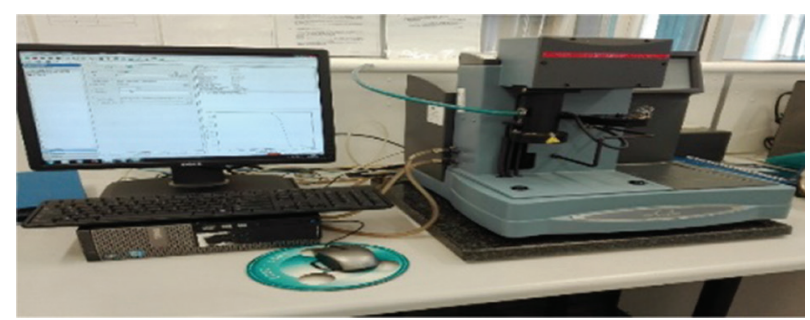

Figure 9: Thermo-gravitational analysis Q500.

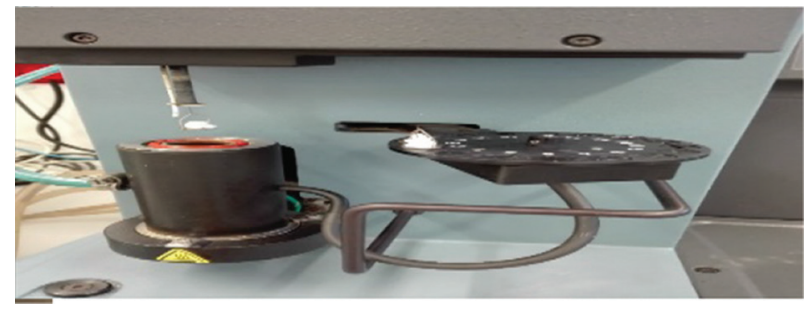

Figure 10: Samples being loaded in a furnace. 


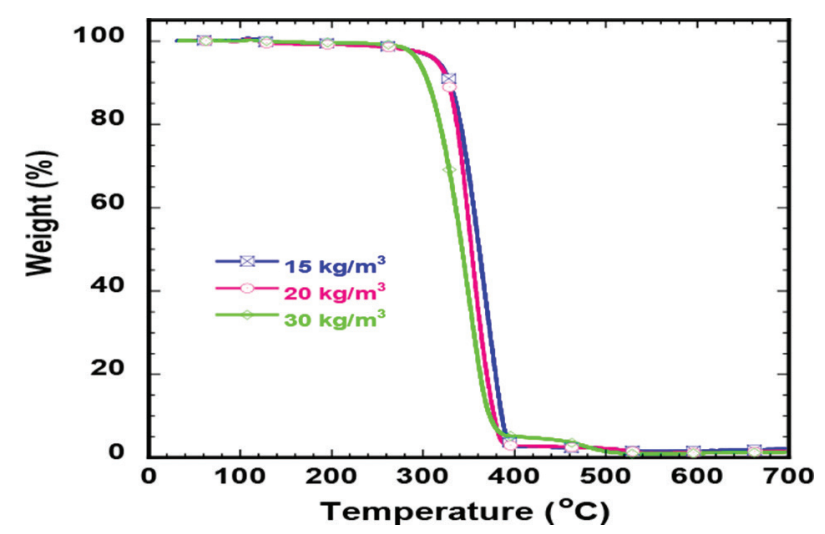

Figure 11: Weight vs temperature graph of EPS samples.

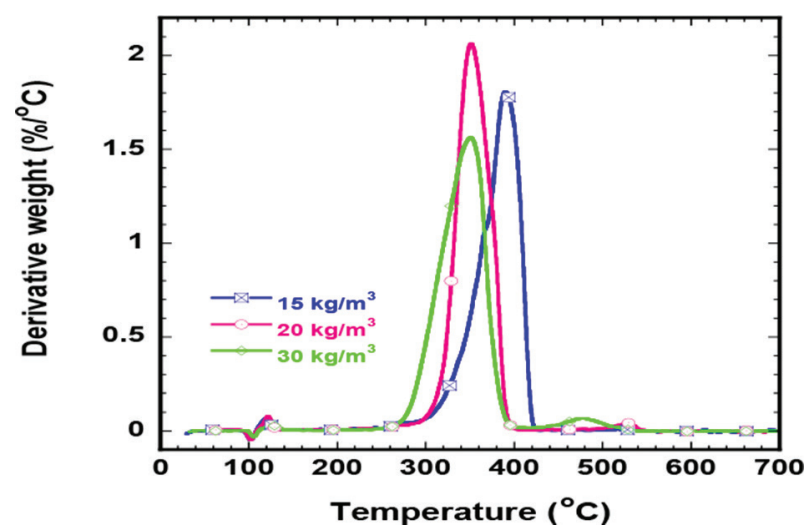

Figure 12: Derivative weight vs temperature graph of EPS samples.

Density of 15

- 1 st run -366.40

- 2nd run-398.72

- 3rd run - 390.30

Average degradation value $=384.14^{\circ} \mathrm{C}$

Density of 20

- 1 st run - 356.41

- 2nd run -342.98

- 3 rd run -351.79

Average degradation value $=350.39^{\circ} \mathrm{C}$ 
Density of 30

- 1 st run -340.50

- 2nd run -345.47

- 3 rd run -351.17

Average degradation value $=345.71^{\circ} \mathrm{C}$.

As the density of EPS increases, the maximum degradation temperature decreases, this is contrary to what would naturally be expected. A natural assumption would be that the higher the density, the lower the susceptibility to being consumed by fire. Fires range up to values in excess of $1000^{\circ} \mathrm{C}$ [8]. The above degradation values indicate that the natural face of EPS would need to be reinforced with a clad layer on top in order to increase its resistance to heat, and also to off-set its degradation value to a greater value.

\subsection{Flexural strength: ASTM C 203-99}

Airborne objects resulting intentionally with the aid of humans or unintentionally as a result of atmospheric interventions pose a serious threat to any wall of any building structure, regardless of the type of material it is made of. It is therefore important that flexural properties of any material used to form the walls of a structure be adequate enough to allow individuals inside the structure to take appropriate action to safety.

Flexural strength is also commonly referred to as the modulus of rupture. Flexure reveals the stress in a material just before it yields during a flexural test. During the flexural test, a rectangular cross-section is placed as a simple beam under centre loading in order to determine its breaking load and therefore its flexural strength.

\subsubsection{Summary of flexural test}

Each specimen was deflected until rupture. The equations used to calculate the flexural strength of each specimen are based on the assumption that the material is uniform. The equations also presume that the stress-strain characteristics below the elastic limit are linearly elastic. The apparatus used for the test is an Instron 5966- k8883. The number of test specimens to be tested is prescribed to be at least four specimens. Ten specimens were prepared for this test and the most comparable results were later considered.

\subsubsection{Procedure}

Each specimen's width and depth were measured to the nearest $0.3 \mathrm{~mm}$ at the centre of the support span as shown in Fig. 13. The dimensions of the test specimen were $100 \times 40 \times 10 \mathrm{~mm}$.

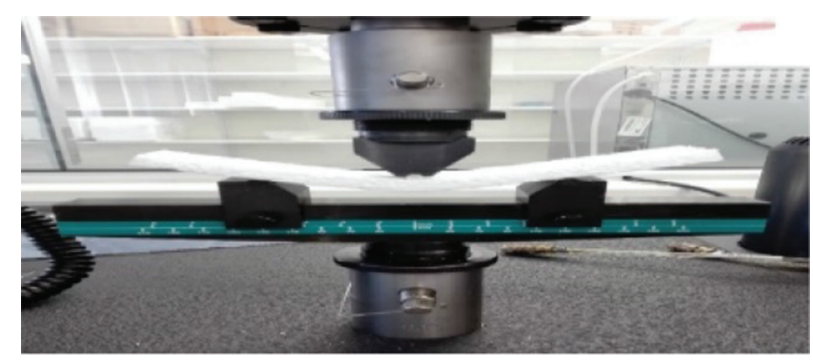

Figure 13: EPS sample being subjected to flexure during the flexural strength test. 
The crosshead rate is calculated as follows

$$
\mathrm{R}=\mathrm{ZL}^{2} / 6 \mathrm{~d}
$$

Flexural strength is calculated by

$$
\mathrm{S}=3 \mathrm{PL} / 2 \mathrm{bd} \mathrm{d}^{2}
$$

\subsubsection{Results}

Instron 5966- k8883 display unit plotted the relevant line graph for each of the samples with varying densities. The performance of each sample with regards to stress and strain is demonstrated in Figs. 14 to 16.
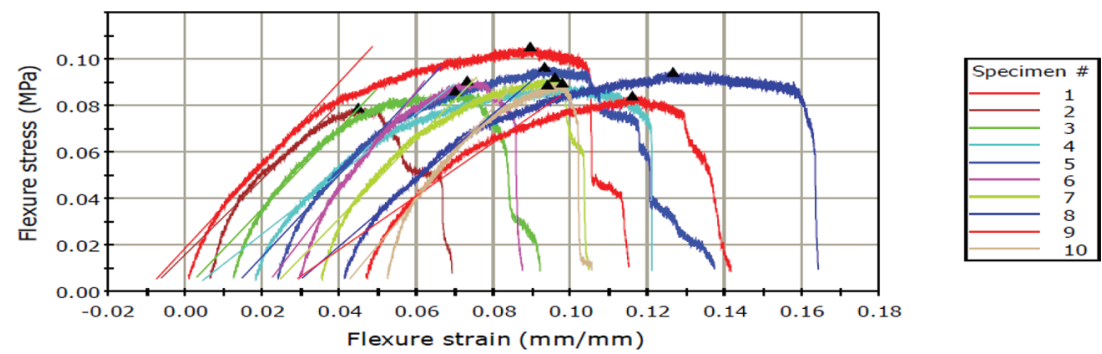

Figure 14: Flexural stress vs flexural strain graph of $15 \mathrm{~kg} / \mathrm{m}^{3}$ samples.
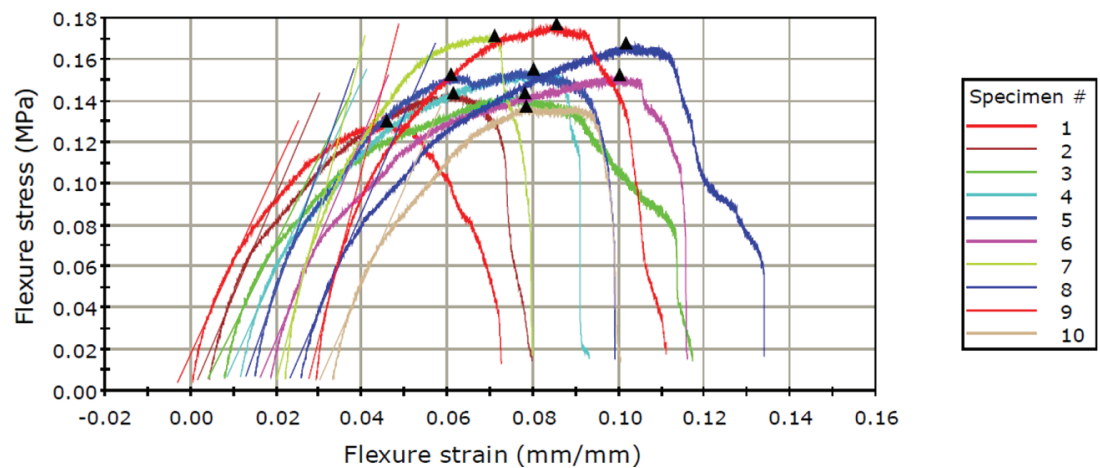

Figure 15: Flexural stress vs flexural strain graph of $20 \mathrm{~kg} / \mathrm{m}^{3}$ samples.
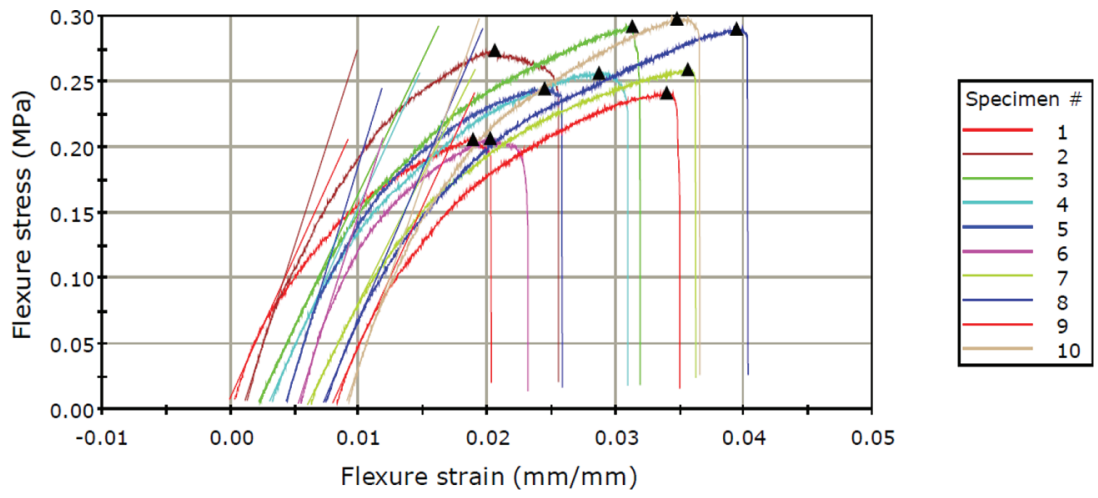

Figure 16: Flexural stress vs flexural strain graph of $30 \mathrm{~kg} / \mathrm{m}^{3}$ samples. 


\subsubsection{Discussion}

The standard requires that at least four specimens be tested, therefore, only four output results of similar nature were considered and are shown in Tables 5 to 7.

Table 5: Reduced stress vs strain results of $15 \mathrm{~kg} / \mathrm{m}^{3}$ samples.

\begin{tabular}{cccccc}
\hline $\begin{array}{c}\text { Thickness } \\
(\mathbf{m m})\end{array}$ & Width (mm) & $\begin{array}{c}\text { Modulus } \\
(\mathbf{E - m o d u l u s}) \\
(\mathbf{M P a})\end{array}$ & $\begin{array}{c}\text { Flexure } \\
\text { stress at } \\
\text { yield (zero } \\
\text { slope) }(\mathbf{M P a})\end{array}$ & $\begin{array}{c}\text { Flexure } \\
\text { strain at } \\
\text { maximum } \\
\text { flexure load } \\
(\mathbf{m m} / \mathbf{m m})\end{array}$ & $\begin{array}{c}\text { Flexure } \\
\text { stress at } \\
\text { maximum } \\
\text { flexure load } \\
(\mathbf{M P a})\end{array}$ \\
\hline 10.00 & 40.00 & 1.78 & 0.11 & 0.09 & 0.11 \\
10.00 & 40.00 & 1.73 & 0.09 & 0.06 & 0.09 \\
10.00 & 40.00 & 1.76 & 0.10 & 0.07 & 0.10 \\
10.00 & 40.00 & 1.71 & 0.09 & 0.06 & 0.09 \\
\hline
\end{tabular}

Table 6: Reduced stress vs strain results of $20 \mathrm{~kg} / \mathrm{m}^{3}$ samples.

\begin{tabular}{cccccc}
\hline $\begin{array}{c}\text { Thickness } \\
(\mathbf{m m})\end{array}$ & Width (mm) & $\begin{array}{c}\text { Modulus } \\
(\text { E-modulus }) \\
(\mathbf{M P a})\end{array}$ & $\begin{array}{c}\text { Flexure } \\
\text { stress at } \\
\text { yield (zero } \\
\text { slope }) \\
(\mathbf{M P a})\end{array}$ & $\begin{array}{c}\text { Flexure } \\
\text { strain at } \\
\text { maximum } \\
\text { flexure load } \\
(\mathbf{m m} / \mathbf{m m})\end{array}$ & $\begin{array}{c}\text { Flexure } \\
\text { stress at } \\
\text { maximum } \\
\text { flexure load } \\
(\mathbf{M P a})\end{array}$ \\
\hline 10.00 & 40.00 & 4.87 & 0.14 & 0.06 & 0.14 \\
10.00 & 40.00 & 4.87 & 0.15 & 0.08 & 0.15 \\
10.00 & 40.00 & 4.76 & 0.17 & 0.08 & 0.17 \\
10.00 & 40.00 & 4.67 & 0.14 & 0.05 & 0.14 \\
\hline
\end{tabular}

Table 7: Reduced stress vs strain results of $30 \mathrm{~kg} / \mathrm{m}^{3}$ samples.

\begin{tabular}{cccccc}
\hline $\begin{array}{c}\text { Thickness } \\
(\mathbf{m m})\end{array}$ & Width (mm) & $\begin{array}{c}\text { Modulus } \\
(\mathbf{E - m o d u l u s}) \\
(\mathbf{M P a})\end{array}$ & $\begin{array}{c}\text { Flexure } \\
\text { stress at } \\
\text { yield (zero } \\
\text { slope) } \\
(\mathbf{M P a})\end{array}$ & $\begin{array}{c}\text { Flexure } \\
\text { strain at } \\
\text { maximum } \\
\text { flexure load } \\
(\mathbf{m m} / \mathbf{m m})\end{array}$ & $\begin{array}{c}\text { Flexure } \\
\text { stress at } \\
\text { maximum } \\
\text { flexure load } \\
(\mathbf{M P a})\end{array}$ \\
\hline 10.00 & 40.00 & 21.52 & 0.21 & 0.02 & 0.21 \\
10.00 & 40.00 & 20.49 & 0.29 & 0.03 & 0.29 \\
10.00 & 40.00 & 21.48 & 0.26 & 0.03 & 0.26 \\
10.00 & 40.00 & 21.36 & 0.24 & 0.03 & 0.24 \\
\hline
\end{tabular}



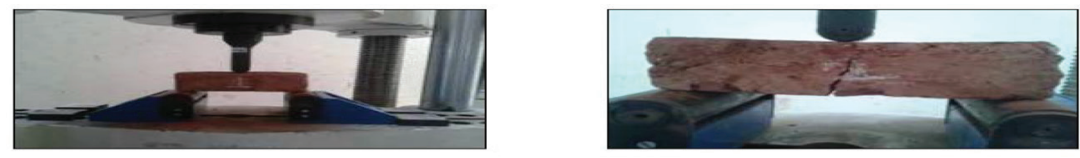

Figure 17: Clay bricks set-up on flexural instrument during the flexural strength test [5].

The difference in the modulus of rupture from a higher density to a lower density is noticeably large. The difference from the lowest modulus of $30 \mathrm{~kg} / \mathrm{m}^{3}$ to the lowest modulus of $20 \mathrm{~kg} / \mathrm{m}^{3}$ is $15.81683 \mathrm{MPa}$. The difference between the lowest modulus of $20 \mathrm{~kg} / \mathrm{m}^{3}$ to $15 \mathrm{~kg} /$ $\mathrm{m}^{3}$ is $2.95991 \mathrm{MPa}$. A study was done in Maharashtra in India to determine the modulus of rupture for clay bricks using a similar set-up as shown in Fig. 17 [5].

The modulus of rupture was calculated using the following formula:

$$
f r=\frac{(1.5 * P * l)}{(b * t 2)}
$$

Where fr is the modulus of rupture, $\mathrm{P}$ the maximum load taken by a specimen, 1 the span of member, $b$ the width of the specimen and $t$ is the thickness of the specimen.

The average value of the modulus of rupture calculated using eqn (5) was $1.185 \mathrm{MPa}$. The average value of the modulus of rupture for the lowest density of EPS considered during the above tests is $1.74659 \mathrm{MPa}$.

\section{CONCLUSION}

From the observation of the live model it can be seen that the individual manufacture of similar EPS dome houses as those constructed by commercial suppliers is possible through a hot wire method. However, from laboratory test results of EPS in its standard form, it is strongly recommended that EPS should always be protected by a facing material, or by complete encapsulation. The data from the TGA shows that if EPS is exposed to temperatures beyond $300^{\circ} \mathrm{C}$, it begins to soften, to contract and finally to melt. Smoke is an important factor in fire. A high density of smoke will inhibit the search for an emergency exit, thereby increasing the risks to occupants. Smoke fumes can also be toxic or have a low oxygen content.

The flexural yield point of EPS bears close resemblance to some aspects of clay bricks. Due to the flexural yield values of EPS comparing favourably with that of clay bricks; it can therefore be seen that there are some positive prospects of using EPS in its standard form as a type of dwelling. Some of the purposes for which such a structure would be advised are on construction sites as a chemical storage unit and for temporary shelter either for disaster alleviation or interim arrangements whilst permanent accommodation is being sought.

\section{REFERENCES}

[1] Expanded Polystyrene Association of Southern Africa, Selection Guide Introducing Expanded Polystyrene, available at http://epsasa.co.za/wp-content/uploads/2018/07/ Selection_Guide_Introducing_EPS.pdf, 2006 (accessed 01 May 2018).

[2] Japan Dome House Co. Ltd, Dome House, available at http://www.i-domehouse.com/, 2018 (accessed 14 May 2018). 
[3] Japan Real Estate, Dome Houses of Japan: Made of Earthquake-Resistant Styrofoam, available at https://resources.realestate.co.jp/living/dome-houses-of-japan-made-ofearthquake-resistant-styrofoam/, 2018 (accessed 20 May 2018).

[4] Meteoblue, Weather archive Pietermaritzburg, available at https://www.meteoblue. com/en/weather/forecast/archive/pietermaritzburg_south-africa_965301?fcstlength=1 m\&year=2018\&month=4, 2018 (accessed 25 April 2018)

[5] Shodhganga, Chapter 3: Characterization of Bricks, available at http://shodhganga. inflibnet.ac.in/bitstream/10603/84281/13/13_chapter3.pdf, 2018 (accessed 06 April 2018).

[6] Hendry. E.A.W., Masonry walls: materials and construction, Elsevier Journal. available from https://ac-els-cdn-com.ezproxy.uct.ac.za/S0950061801000198/1-s2.0-S09500618 01000198-main.pdf?_tid=a39993b1-4d3b-4173-9eaa-63f64190678c\&acdnat= 1522915008_d09f9905858b2bf29a88d5cd84248021, 2001 (accessed 15 March 2018).

[7] Home Energy Saver, Popular Mechanics, p. 70, September 1977.

[8] Target fire. What is the Temperature of Fire? available at https://www.target-fire.co.uk/ news/what-is-the-temperature-of-fire/, 2018 (accessed 04 June 2018). 